\title{
Características da carcaça e alometria dos tecidos de cabritos F1 Boer $\times$ Saanen ${ }^{1}$
}

\author{
José Morais Pereira Filho ${ }^{2}$, Kleber Tomás de Resende ${ }^{3}$, Izabelle Auxiliadora Molina de \\ Almeida Teixeira ${ }^{3}$, Américo Garcia da Silva Sobrinho ${ }^{3}$, Enrique Alejandro Yáñez ${ }^{4}$, Ângela \\ Cristina Dias Ferreira ${ }^{3}$
}

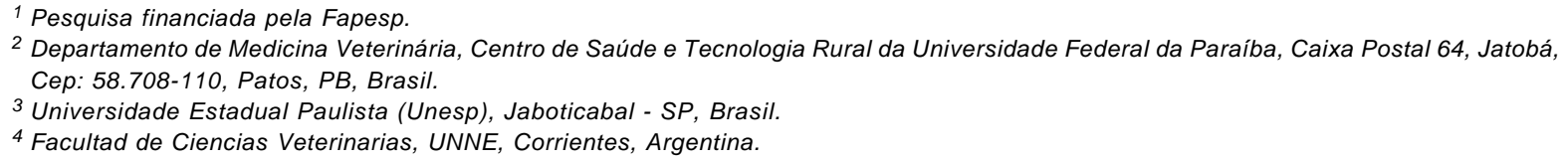

RESUMO - Com o objetivo de avaliar as características de carcaça e a alometria dos cortes comerciais e dos tecidos de cabritos F1 Boer $\times$ Saanen, 35 animais foram abatidos ao atingirem 5, 10, 15, 20 e $25 \mathrm{~kg}$ de peso vivo (PV). A dieta dos animais foi composta de leite de vaca nos primeiros 49 dias e ração à vontade do sétimo dia até o abate. Os cortes foram obtidos após o resfriamento da carcaça e a perna foi dissecada em músculo, osso e gordura. O PV teve efeito linear decrescente no rendimento de carcaça fria e na área de olho-de-lombo por kg de carcaça. Os pesos de perna, paleta e pescoço em relação à carcaça fria decresceram linearmente, mas houve efeito quadrático sobre o rendimento de costelas e lombo. O crescimento de paleta, pescoço e perna foi isométrico $(b=1)$ ao do corpo, enquanto o das costelas e do lombo foi mais lento ( $b \neq 1)$. Os músculos da perna cresceram igualmente, a gordura mais lenta e os ossos mais rapidamente que a perna, enquanto o desenvolvimento da gordura subcutânea foi mais tardio que o da intermuscular. Para obtenção de carcaça de 8 a $11 \mathrm{~kg}$ com rendimento superior a $44 \%$, boa proporção de músculo e gordura com menor perda durante o resfriamento, recomenda-se abater os animais com PV entre 20 e $25 \mathrm{~kg}$, mas, se o objetivo for carcaça de menor peso, o abate dos animais deve ser feito ao final do aleitamento com aproximadamente $10 \mathrm{~kg}$ de peso corporal.

Palavras-chave: crescimento, gordura, lombo, músculo, perna

\section{Carcass traits and tissue allometry in Boer $\times$ Saanen kids}

\begin{abstract}
Thirty-five male kids Boer $\times$ Saanen kids were shaughtered at 5, 10, 15, 20 e $25 \mathrm{~kg}$ BW to evaluate the carcass traits and commercial cuts and tissues allometry. The diet fed to the animas was composed by cow milk in the first 49 days and ad libitum ration from the seventh day until slaughter. The cuts were obtained after cooling of the carcass and the leg dissected in muscle, bone and fat. The body weight showed a negative linear effect on cold carcass dressing and the loin-eye area/kg of carcass. The weights of leg, shoulder and neck in relation to cold carcass linearly decrease however there was a quadratic effect on ribs and loin yield. The shoulder, neck and leg showed an isometric growth $(b=1)$ with the body, while ribs and loin was slower $(b \neq 1)$. The growth of leg muscle was isometric, fat slower and faster then leg, while the subcutaneous fat was slower than the intermuscle fat. To achieve a carcass with 8 to $11 \mathrm{~kg}$ with superior yield of $44 \%$, good muscle and fat proportion with lesser loss during the cooling, it is recommended to slaughter the animals weighting between 20 and $25 \mathrm{~kg}$. BW. However, if the objective is to obtain carcass of slower weight, the male goat kids should be slaughtered at the end of the milking period, around $10 \mathrm{~kg} \mathrm{BW}$.
\end{abstract}

Key Words: fat, growth, leg, loin, muscle

\section{Introdução}

A exploração de caprinos no Brasil pode ser compreendida sob a ótica de dois níveis tecnológicos. O primeiro é predominante no Nordeste do País e tem caráter de subsistência, com pouco ou nenhum controle zootécnico. O segundo é mais freqüente na Região Sudeste e consiste na criação de caprinos de raças leiteiras e, mais recentemente, na produção de carne de cabrito.

Nos últimos anos, os caprinocultores da Região Sudeste têm utilizado em seus rebanhos leiteiros reprodutores Boer para cruzamento com parte das fêmeas leiteiras, o bjetivando

Este artigo foi recebido em 12/3//2007 e aprovado em 1/11/2007.

Correspondências devem ser enviadas para jmorais@cstr.ufcg.edu.br. 
aumentar o ganho de peso e o rendimento de carcaça e disponibilizando machos e fêmeas para o abate (Pereira Filho et al., 2005). Paralelamente, os consumidores têm buscado alimentos mais saudáveis, preferencialmente carnes magras e com boas características organolépticas. Diante dessa realidade, o caprino apresenta-se como boa alternativa, principalmente pelos baixos teores de gordura, colesterole ácido graxo saturado em sua carne em comparação à carne dos demais ruminantes.

Animais da raça Boer destacam-se pela sua excelente conformação, pelo crescimento rápido, pelo elevado índice de fertilidade e prolificidade. Além disso, são facilmente adaptáveis às condições ambientais e imprimem aos descendentes suas características de produtor de carne de boa qualidade (Sousa et al., 1998; Malan, 2000), podendo constituir-se em boa alternativa para cruzamentos com outras raças e/ou tipos raciais criados no Brasil. Assim, torna-se necessário conhecer as características de carcaça e dos cortes comerciais dos produtos desses cruzamentos em diferentes pesos de abate, as quais, associadas ao estudo do crescimento tecidual, permitirão inferir sobre o melhor momento para o abate. Nessa perspectiva, Yáñez (2002) estimou a curva de crescimento de cabritos Saanen de 5 a $35 \mathrm{~kg}$ de PV e concluiu que é mais econômico comercializar carcaça de $9 \mathrm{~kg}$ para animais não-castrados e com mais de $12 \mathrm{~kg}$ para animais castrados.

Segundo Hammond (1966), o crescimento pode ser entendido como o aumento de peso até o animal se tornar adulto. Essa definição, apesar de simples, não tira a complexidade do tema, pois, a partir do modelo alométrico proposto por Huxley (1932), todas as variáveis são reduzidas ao valor do coeficiente de crescimento, mas, dependendo da amplitude dos pesos estudados, alguns aspectos ao longo da curva podem não ser explicados.

De acordo com Sainz (2000), os fatores que mais influenciam a qualidade da carcaça e da carne são raça, sexo, idade e nutrição. Bueno et al. (1997), em pesquisa com cabritos Saanen abatidos com PV médio de 11,00; 16,30 e $22,00 \mathrm{~kg}$, observaram efeito linear crescente para peso e rendimento de carcaça quente e fria, área de olho-de-lombo, peso e proporção de músculo e de gordura, enquanto o rendimento de traseiro, a proporção de osso e a relação músculo:gordura reduziram linearmente.

No Brasil, a qualidade da carcaça e o crescimento relativo dos cortes comerciais e dos tecidos músculo, osso e gordura na espécie caprina ainda são pouco estudados. No entanto, é importante conhecer a alometria dos componentes que determinam a qualidade da carcaça para se inferir sobre o peso ou a condição fisiológica que permitem atender às exigências do mercado consumidor e contribuir para a sustentabilidade econômica da atividade. Este trabalho foi realizado com o objetivo de avaliar as características de carcaça e a alometria dos cortes comerciais e dos tecidos da perna de cabritos F1 Boer $\times$ Saanen.

\section{Material e Métodos}

O trabalho foi realizado no Setor de Caprinocultura da Faculdade de Ciências Agrárias e Veterinárias da Universidade Estadual Paulista, em Jaboticabal, São Paulo, utilizando-se 35 cabritos não-castrados F1 Boer $\times$ Saanen. Os animais foram abatidos ao atingirem 5, 10, 15, 20 e $25 \mathrm{~kg}$ de peso vivo (PV), constituindo-se nos tratamentos.

Durante o aleitamento, o manejo alimentar consistiu do fornecimento de colostro de vaca durante dois dias, seguido do fornecimento de 1,50 L de leite de vaca, dividido em duas refeições diárias. Os animais foram desmamados no 50 o dia de vida. A dieta sólida (Tabela 1) foi formulada com base nas exigências em proteína e energia metabolizável descritas pelo AFRC (1998) para ganho de $150 \mathrm{~g}$, a qual foi fornecida à vontade a partir do $7 \underline{0}$ dia, de modo a permitir $20 \%$ de sobras.

A ração foi fornecida às $7 \mathrm{~h}$, com pesagem diária das sobras e ajuste da quantidade oferecida. Os animais foram pesados semanalmente e, ao atingirem os pesos de abate, foram submetidos a jejum de sólidos durante 24 horas e a jejum de líquidos durante 16 horas, com pesagem antes e após o jejum, para obtenção, respectivamente, do peso vivo (PV) e do peso em jejum (PJ).

$\mathrm{O}$ abate ocorreu mediante descarga elétrica e sangria, seguidas de esfola e retirada dos órgãos. O trato gastrintestinal foi esvaziado e limpo para obtenção do peso do corpo vazio (PCV), que foi calculado subtraindo-se do PJ os pesos referentes ao conteúdo gastrintestinal e ao líquido contido na bexiga e vesícula biliar.

Tabela 1 - Proporção dos ingredientes e composição bromatológica da ração

\begin{tabular}{|c|c|c|c|}
\hline Ingrediente & $\%$ & Componente & $\%$ \\
\hline $\begin{array}{l}\text { Feno da planta } \\
\text { de milho }\end{array}$ & 46,88 & Matéria seca & 89,32 \\
\hline Milho moído & 25,91 & Proteína bruta ${ }^{1}$ & 16,50 \\
\hline Farelo de soja & 19,32 & Extrato etéreo ${ }^{1}$ & 3,56 \\
\hline $\begin{array}{l}\text { Melaço de } \\
\text { cana-de-açúcar }\end{array}$ & 4,29 & $\begin{array}{c}\text { Energia metabolizável } \\
(\mathrm{Mcal} / \mathrm{kg} \mathrm{MS})^{2}\end{array}$ & 2,46 \\
\hline Óleo de soja & 0,81 & $\begin{array}{c}\text { Fibra em detergente } \\
\text { neutro }{ }^{1}\end{array}$ & 48,82 \\
\hline Núcleo mineral & 1,99 & $\begin{array}{c}\text { Fibra em detergente } \\
\text { ácido }\end{array}$ & 17,72 \\
\hline Calcário calcítico & 0,80 & Cálcio ${ }^{1}$ & 0,65 \\
\hline Total & 100,00 & Fósforo $^{1}$ & 0,32 \\
\hline
\end{tabular}

1 Valores expressos com base na matéria seca.

2 Estimada segundo Teixeira (2004). 
A carcaça foi obtida após a separação das mãos e dos pés na articulação carpometacarpiano e tarsometatarsiano, respectivamente, obtendo-se o peso da carcaça quente (PCQ). Todos os componentes do corpo do animal não incluídos no peso da carcaça foram denominados "nãocomponentes da carcaça" e foram obtidos subtraindo-se o PCQ do PCV. As carcaças foram mantidas em câmara fria por 24 horas, em temperatura de $5^{\circ} \mathrm{C}$ para obtenção do peso da carcaça fria (PCF).

Os parâmetros avaliados na carcaça foram PCQ, PCF, perda por resfriamento (PR), área de olho-de-lombo (AOL) e AOL por kg de carcaça fria (AOL/kgCF). Para determinação da AOL, foi utilizada a Grade-Unesp recomendada por Yáñez et al. (2006a). As estimativas dos rendimentos de carcaça quente (RCQ) e de carcaça fria (RCF) e do rendimento biológico (RB) foram obtidas de acordo com metodologia descrita por Osório et al. (1998).

A carcaça foi seccionada longitudinalmente e a meiacarcaça esquerda foi dividida em cinco cortes: perna, lombo, costelas, paleta e pescoço. Os cortes foram realizados segundo adaptações das metodologias de Colomer-Rocher et al. (1987), Osório et al. (1998) e Yáñez (2002). As pernas foram congeladas a $-20^{\circ} \mathrm{C}$ e, posteriormente, foram descongeladas e dissecadas em músculo, osso e gordura.

O delineamento experimental foi inteiramente casualizado, com cinco tratamentos e sete repetições. Os dados foram submetidos a análises de variância e de regressão, segundo os procedimentos Proc Glm e Proc Reg do SAS (1999).

Para avaliar o crescimento alométrico dos cortes e dos tecidos, utilizou-se a equação alométrica $Y=a X^{b}$, que foi linearizada por transformação logarítmica pelo modelo $\ln \mathrm{Y}=\ln \mathrm{a}+\mathrm{b} \ln \mathrm{X}$, descrito por Huxley (1932), em que: $\mathrm{Y}=$ peso do componente do peso vivo (carcaça e nãocomponentes da carcaça), do corte comercial (perna, lombo, costelas, pescoço e paleta) ou do tecido (músculo, osso e gordura) a ser avaliado; $\mathrm{X}=$ peso de corpo vazio ou peso da perna; $a$ = intercepto do logaritmo da regressão linear sobre Y e b; e b = coeficiente de alometria. Para obtenção dos coeficientes, os dados foram submetidos a análises pelo procedimento Proc Nlin do SAS (1999). Para verificação da hipótese (Ho) b=1, adotou-se o procedimento descrito por Furusho-Garcia et al. (2006), utilizando-se o teste t de Student, em que: se $b=1$, os coeficientes de crescimento de $\mathrm{X}$ e $\mathrm{Y}$ foram semelhantes e, portanto, $\mathrm{b}$ foi denominado isogônico; se $b \neq 1$, o crescimento foi considerado heterogônico, podendo ser positivo ( $\mathrm{se} b>1$ ) e considerado de crescimento tardio, ou negativo $(\mathrm{se} b<1)$ e definido como crescimento precoce.

\section{Resultados e Discussão}

O peso ao nascer e a idade de abate foram testados como co-variáveis, mas não houve efeito significativo. Com exceção do rendimento biológico, as demais variáveis foram influenciadas $(\mathrm{P}<0,05)$ pelo peso vivo dos cabritos, que teve efeito linear crescente sobre o peso em jejum (PJ), o peso de corpo vazio (PCV), o peso de carcaça quente (PCQ), o peso de carcaça fria (PCF) e a área de olho-delombo (AOL), além de efeito linear decrescente sobre o rendimento de carcaça fria (RCF), a perda no resfriamento (PR) e a AOL/kgCF e efeito quadrático sobre o rendimento de carcaça quente (RCQ) (Tabela 2).

O aumento linear pode ser entendido como resposta direta do crescimento animal, visto que animais de maiores pesos vivos implicam a obtenção de maiores PJ e PCV, o que refletiu em PCQ, PCF e AOL mais elevados. A relação linear negativa do $\mathrm{PV}$ com o RCF e AOL/kgCF pode estar relacionada à idade e ao peso ao nascer dos animais de $5 \mathrm{~kg}$ de PV (Pereira Filho et al., 2001). Com o lento desenvolvimento dos pré-estômagos dos animais de até $10 \mathrm{~kg}$, que continham pouco conteúdo gastrintestinal, o baixo peso dos órgãos e das vísceras repercutiu em elevado rendimento de carcaça, enquanto, nos animais de 20 e $25 \mathrm{~kg}$ de PV, o rendimento de carcaça foi constante.

A relação quadrática entre o peso vivo e o RCQ pode ser explicada pelo elevado rendimento de carcaça dos animais de 5 e $10 \mathrm{~kg}$, seguido da redução no rendimento de carcaça dos animais de 15, 20 e $25 \mathrm{~kg}$ de PV. Todavia, esse efeito não se repetiu no RCF, o que pode ser explicado pelo efeito linear negativo sobre a PR, principalmente nas carcaças dos animais de 5 e $10 \mathrm{~kg}$, que, de acordo com Trindade et al. (2001), apresentavam 28,21 e 30,92\% de MS e 6,88 e $9,14 \%$ do peso corporal em gordura, resultando em pouca proteção da carcaça e, conseqüentemente, em maior perda de água. Em animais mais pesados e próximos à maturidade fisiológica, ocorre redução na taxa de deposição de músculo e aumento na de gordura, refletindo em menor proporção de água, maior concentração de gordura, melhor acabamento da carcaça e diminuição das perdas por resfriamento (Boggs et al., 1998).

O crescimento linear da AOL em valores absolutos e o decréscimo da $\mathrm{AOL} / \mathrm{kgCF}$ corroboram os resultados obtidos em ovinos (Bueno et al., 2000) e caprinos (Sainz, 2000) de que o crescimento do músculo Longissimus dorsi é um bom parâmetro para a avaliação do crescimento animal. Entretanto, autores como Butterfeld (1988) e Boggs et al. (1998) ressaltaram que o entendimento dessas relações é mais evidente quando a avaliação é feita até a maturidade fisiológica dos animais. 
Tabela 2 - Peso em jejum (PJ), peso de corpo vazio (PCV), peso da carcaça quente (PCQ), peso da carcaça fria (PCF), rendimentos de carcaça quente $(R C Q)$ e de carcaça fria $(R C F)$, rendimento biológico $(R B)$, perda no resfriamento $(P R)$ e área de olho-delombo (AOL) de cabritos F1 Boer $\times$ Saanen

\begin{tabular}{|c|c|c|c|c|c|c|c|}
\hline & \multicolumn{5}{|c|}{ Peso vivo (kg) } & \multirow[t]{2}{*}{ Equação de regressão } & \multirow[t]{2}{*}{$\mathrm{r}^{2}$} \\
\hline & 5 & 10 & 15 & 20 & 25 & & \\
\hline PJ (kg) & 5,25 & 9,50 & 14,26 & 18,78 & 23,68 & $\hat{\mathrm{Y}}=0,451+0,923 \mathrm{X}$ & 0,99 \\
\hline PCV (kg) & 5,09 & 8,66 & 11,62 & 15,39 & 19,79 & $\hat{\mathrm{Y}}=1,269+0,723 \mathrm{X}$ & 0,98 \\
\hline PCQ (kg) & 2,88 & 4,84 & 6,62 & 8,63 & 11,15 & $\hat{\mathrm{Y}}=0,731+0,406 \mathrm{X}$ & 0,97 \\
\hline PCF (kg) & 2,50 & 4,57 & 6,24 & 8,32 & 10,82 & $\hat{\mathrm{Y}}=0,377+0,407 \mathrm{X}$ & 0,98 \\
\hline RCQ (\%) & 55,06 & 51,02 & 46,42 & 45,95 & 47,11 & $\hat{Y}=62,667-1,665 X+0,041 X^{2}$ & 0,81 \\
\hline $\mathrm{RCF}(\%)$ & 47,44 & 48,16 & 43,74 & 44,28 & 45,70 & $\hat{\mathrm{Y}}=48,07-0,147 \mathrm{X}$ & 0,17 \\
\hline $\mathrm{RB}(\%)$ & 56,70 & 55,97 & 56,94 & 56,09 & 56,36 & NS & \\
\hline PR $(\%)$ & 13,54 & 5,63 & 5,55 & 3,62 & 3,01 & $\hat{Y}=13,193-0,461 X$ & 0,46 \\
\hline $\mathrm{AOL}\left(\mathrm{cm}^{2}\right)$ & 3,15 & 4,35 & 6,76 & 7,19 & 8,94 & $\hat{Y}=1,776+0,287 X$ & 0,81 \\
\hline $\mathrm{AOL} / \mathrm{kgCF} *$ & 0,63 & 0,45 & 0,47 & 0,38 & 0,39 & $\hat{\mathrm{Y}}=0,644-0,012 \mathrm{X}$ & 0,29 \\
\hline
\end{tabular}

$\hat{Y}=$ variável dependente; $\mathrm{X}=$ peso vivo; $\mathrm{r}^{2}$ = coeficiente de determinação; $N S$ = não-significativo; ${ }^{*}$ = área de olho-de-lombo por kg de carcaça fria.

Tabela 3 - Pesos dos cortes comerciais e proporções dos cortes comerciais na carcaça de cabritos F1 Boer $\times$ Saanen em relação ao peso da carcaça fria

\begin{tabular}{|c|c|c|c|c|c|c|c|}
\hline \multirow[t]{3}{*}{ Corte $(\mathrm{g})$} & \multicolumn{5}{|c|}{ Peso da carcaça fria $(\mathrm{kg})$} & \multirow[t]{3}{*}{ Equação de regressão } & \multirow[t]{3}{*}{$r^{2}$} \\
\hline & $2,43^{1}$ & $4,59^{1}$ & $6,29^{1}$ & $8,43^{1}$ & $10,95^{1}$ & & \\
\hline & $(5)^{3}$ & $(10)^{3}$ & $(15)^{3}$ & $(20)^{3}$ & $(25)^{3}$ & & \\
\hline Perna & 392 & 747 & 1.020 & 1.329 & 1.716 & $\hat{\mathrm{Y}}=28,6+154,7 \mathrm{X}$ & 0,98 \\
\hline Lombo & 124 & 237 & 340 & 476 & 704 & $\hat{Y}=41,7+28,0 X+2,9 X^{2}$ & 0,97 \\
\hline Costelas & 290 & 562 & 843 & 1.141 & 1.481 & $\hat{Y}=60,0+141,4 X$ & 0,97 \\
\hline Paleta & 274 & 518 & 641 & 837 & 1.036 & $\hat{\mathrm{Y}}=80,1+88,7 \mathrm{X}$ & 0,97 \\
\hline Pescoço & 136 & 233 & 299 & 430 & 539 & $\hat{\mathrm{Y}}=14,2+47,9 \mathrm{X}$ & 0,90 \\
\hline \multicolumn{8}{|l|}{ Corte $(\%)$} \\
\hline Perna & 32,16 & 32,51 & 32,47 & 31,57 & 31,34 & $\hat{Y}=32,771-0,119 X$ & 0,16 \\
\hline Lombo & 10,21 & 10,32 & 10,79 & 11,29 & 12,87 & $\hat{Y}=10,594-0,248 X+0,041 X^{2}$ & 0,65 \\
\hline Costelas & 23,89 & 24,46 & 26,82 & 27,07 & 27,04 & $\hat{Y}=21,097+1,198 X-0,059 X^{2}$ & 0,56 \\
\hline Paleta & 22,57 & 22,56 & 20,40 & 19,87 & 18,92 & $\hat{\mathrm{Y}}=23,869-0,464 \mathrm{X}$ & 0,74 \\
\hline Pescoço & 11,17 & 10,15 & 9,52 & 10,19 & 9,83 & $\hat{Y}=11,048-0,131 X$ & 0,14 \\
\hline
\end{tabular}

${ }^{1}$ Peso da carcaça fria obtido pela recomposição dos cortes comerciais; ()$^{3}$ peso vivo; $\hat{Y}=$ variável dependente; $X=$ peso da carcaça fria; $r^{2}=$ coeficientes de determinação.

Observou-se efeito linear positivo entre o PCF e os pesos de perna, paleta, pescoço e costelas, enquanto o lombo apresentou relação quadrática (Tabela 3). Todavia, em termos percentuais, observou-se decréscimo linear de perna, paleta e pescoço em relação ao PCF, além de efeito quadrático para costelas e lombo.

$\mathrm{O}$ efeito quadrático do PCF sobre as proporções de costelas e lombo na carcaça pode ser reflexo do crescimento tardio desses cortes em relação ao corpo. Esse comportamento torna-se notório, em razão das menores proporções desses cortes nas carcaças de 2,43 a 6,29 kg (5 a $15 \mathrm{~kg}$ de PV) e das maiores participações nas carcaças dos animais de 20 e $25 \mathrm{~kg}$ de PV. Esses resultados devem ser interpretados como duas fases distintas: a primeira, para carcaças de 2,43 a $6,29 \mathrm{~kg}$, caracterizadas pelo elevado ganho de massa muscular; e a segunda, pelo aumento na deposição de gordura, especialmente nas carcaças de $10,95 \mathrm{~kg}$. Comportamento semelhante foi relatado por Yáñez et al. (2007), em pesquisa com cabritos Saanen de 5 a $35 \mathrm{~kg}$ de PV. Esses autores verificaram aumento na taxa de deposição de gordura a partir dos $8,7 \mathrm{~kg}$ de carcaça, correspondendo a $21 \mathrm{~kg}$ de PV.

Os resultados comprovaram aumento linear da massa muscular em relação ao tecido ósseo à medida que aumentou o peso da perna (PP), enquanto, para as relações M:G e O:G, o efeito foi quadrático. $\mathrm{O}$ efeito linear entre o $\mathrm{PP}$ e a relação 
Tabela 4 - Relações músculo:osso (M:O), músculo:gordura (M:G) e osso:gordura (O:G) da perna de cabritos F1 Boer × Saanen

\begin{tabular}{|c|c|c|c|c|c|c|c|}
\hline \multirow[t]{3}{*}{ Item } & \multicolumn{5}{|c|}{ Peso da perna (g) } & \multirow[t]{3}{*}{ Equação de regressão } & \multirow[t]{3}{*}{$\mathrm{r}^{2}$} \\
\hline & $351^{1}$ & $682^{1}$ & $931^{1}$ & $1221^{1}$ & $1567^{1}$ & & \\
\hline & $(5)^{3}$ & $(10)^{3}$ & $(15)^{3}$ & $(20)^{3}$ & $(25)^{3}$ & & \\
\hline \multicolumn{8}{|c|}{ Relação (g/g) } \\
\hline $\mathrm{M}: \mathrm{O}$ & 2,29 & 3,04 & 3,16 & 3,69 & 3,96 & $\hat{Y}=1,902+0,0014 X$ & 0,84 \\
\hline $\mathrm{M}: \mathrm{G}$ & 22,98 & 15,87 & 13,06 & 10,42 & 8,00 & $\hat{Y}=34,399-0,035 X+0,000012 X^{2}$ & 0,71 \\
\hline $\mathrm{O}: \mathrm{G}$ & 10,33 & 5,26 & 4,14 & 2,81 & 2,03 & $\hat{\mathrm{Y}}=17,401-0,023 \mathrm{X}+0,000008 \mathrm{X}^{2}$ & 0,78 \\
\hline
\end{tabular}

${ }^{1}$ Peso da perna obtido pela recomposição dos tecidos dissecados; ()$^{3}$ peso vivo; $\hat{Y}=$ variável dependente; $X=$ peso da perna; $r^{2}=$ coeficientes de determinação.

M:O refletem o crescimento heterogônico negativo do tecido ósseo e isogônico do músculo. Por outro lado, o efeito quadrático para a relação $\mathrm{M}: \mathrm{G}$ reflete a redução na taxa de deposição de músculo com o aumento na deposição de gordura à medida que os animais ganharam peso.

A relação O:G foi influenciada de forma quadrática pelo peso de abate e caracterizada pelo elevado peso dos ossos da perna dos animais de 5 e $10 \mathrm{~kg}$ e pelo aumento do peso da gordura da perna dos cabritos de 20 e $25 \mathrm{~kg}$ de PV. Esses resultados corroboram os obtidos por Mahgoub \& Lu (1998), que estudaram comparativamente a composição corporal, o desenvolvimento e a distribuição dos tecidos na carcaça de ovinos e caprinos Omani abatidos com 18 e $28 \mathrm{~kg}$ de PV e observaram comportamento semelhante para ambas as espécies.

As proporções de gordura total, de gordura subcutânea e de gordura intermuscular aumentaram linearmente $(\mathrm{P}<0,05)$ com PP dos cabritos, enquanto as relações proporcionais do músculo e do osso foram quadráticas (Tabela 5). Warmington \& Kirton (1990) relataram que o peso ao nascer, o número de crias por parto e a diferença de peso entre os cabritos de mesmo parto influenciam o desempenho dos animais, principalmente na fase de aleitamento.A diminuição da proporção de osso e o aumento na de músculo da perna dos animais de $10 \mathrm{~kg}$ em relação à perna dos cabritos de $5 \mathrm{~kg}$ de PV podem ser reflexo do desenvolvimento fetal e do período de aleitamento. Em parte, o efeito quadrático pode ter ocorrido em virtude da grande variação nas proporções de osso e de músculo da perna dos animais de 5 e de $10 \mathrm{~kg}$ de PV.

Durante a dissecação da perna, os tecidos não identificados, como músculo, osso ou gordura, foram classificados como outros tecidos e incluídos na recomposição do peso da perna, no entanto, não foram avaliados, razão pela qual a totalização dos percentuais de músculo, osso e gordura (Tabela 5) não atingiu $100 \%$.

Os coeficientes de alometria 1,23 das costelas e 1,27 do lombo foram maiores que os do corpo (Tabela 6) e caracterizaram-se como crescimento heterogônico positivo, o que explica a relação quadrática do PCF com o rendimento das costelas e do lombo (Tabela 3). Colomer-Rocher et al. (1992), em pesquisa com caprinos Saanen abatidos com PV de 4,7 a $115 \mathrm{~kg}$, constataram que a paleta e a perna cresceram mais rápido que o corpo, enquanto as costelas, o flanco e o pescoço cresceram mais lentamente, fato explicado pela maior deposição de gordura, principalmente na fase final da maturidade fisiológica.

Os coeficientes de alometria da carcaça e dos nãocomponentes da carcaça foram, respectivamente, 1,04 e 0,97 , estatisticamente iguais ao do corpo, o que pode ser associado à relação entre o peso da carcaça e do corpo vazio, que resultou em RB estatisticamente iguais (Tabela 2). Esses resultados são semelhantes aos obtidos por Mahgoub \& Lodge (1996) para carcaça de animais castrados, nãocastrados e fêmeas da raça Omani Batina com PV de 11, 18 e $28 \mathrm{~kg}$. Yáñez (2002), em pesquisa com cabritos Saanen de 5 a $35 \mathrm{~kg}$ de $P V$, divididos em não-castrados de 5 a $20 \mathrm{~kg}$ e castrados de 20 a $35 \mathrm{~kg}$, obteve coeficientes alométricos de 1,08 para carcaça e de 0,93 para os não-componentes da carcaça, fato associado à redução do rendimento biológico que ocorreu aos $21 \mathrm{~kg}$ de PV.

$\mathrm{O}$ peso ideal para o abate é aquele que atende às exigências dos consumidores, que, nos últimos anos, têm preferido carnes com menor conteúdo de gordura. Todavia, Schönfeeld et al. (1993) afirmaram que, além da castração, a idade e o peso de abate são fatores determinantes da qualidade da carne de caprinos e verificaram melhor qualidade na carne de animais jovens.

Neste estudo, o músculo cresceu semelhantemente à perna e ao corpo, o osso apresentou crescimento heterogônico negativo e a gordura heterogônico positivo (Tabela 7), de modo semelhante aos resultados obtidos por Yáñez (2002) em cabritos Saanen de 5 a 35 kg de PV e aos observados por Colomer-Rocher et al. (1992) em animais Saanen de 2,30 a $51,80 \mathrm{~kg}$ de carcaça.

O crescimento precoce ou isogônico da maioria dos não-componentes da carcaça (órgãos, vísceras, cabeça, patas) e a participação desses tecidos no PCV explica, em 
Tabela 5 - Composição tecidual da perna de cabritos F1 Boer $\times$ Saanen

\begin{tabular}{|c|c|c|c|c|c|c|c|}
\hline \multirow[t]{3}{*}{ Item } & \multicolumn{5}{|c|}{ Peso da perna $(\mathrm{g})$} & \multirow[t]{3}{*}{ Equação de regressão } & \multirow[t]{3}{*}{$\mathrm{r}^{2}$} \\
\hline & $351^{1}$ & $682^{1}$ & $931^{1}$ & $1.221^{1}$ & $1.567^{1}$ & & \\
\hline & $(5)^{3}$ & $(10)^{3}$ & $(15)^{3}$ & $(20)^{3}$ & $(25)^{3}$ & & \\
\hline Músculo & 65,67 & 69,21 & 69,43 & 69,93 & 69,11 & $\hat{Y}=61,712+0,0139 X-0,0000058 X^{2}$ & 0,52 \\
\hline Osso & 28,88 & 22,75 & 22,02 & 19,04 & 17,58 & $\hat{\mathrm{Y}}=35,011-0,020 \mathrm{X}+0,0000058 \mathrm{X}^{2}$ & 0,91 \\
\hline Gordura total & 3,23 & 4,65 & 5,33 & 6,87 & 8,81 & $\hat{\mathrm{Y}}=1,484+0,0045 \mathrm{X}$ & 0,80 \\
\hline GS & 1,48 & 1,96 & 2,76 & 3,89 & 5,21 & $\hat{Y}=0,094+0,0031 X$ & 0,83 \\
\hline GI & 1,76 & 2,69 & 2,59 & 2,99 & 3,61 & $\hat{\mathrm{Y}}=1,390+0,0014 \mathrm{X}$ & 0,45 \\
\hline
\end{tabular}

1 Peso da perna obtido pela recomposição dos tecidos dissecados; $\left(\right.$ ) ${ }^{3}$ peso vivo; $\hat{Y}=$ variável dependente; $X=$ peso da perna; $r^{2}=$ coeficiente de determinação: GS = gordura subcutânea; GI = gordura intramuscular.

Tabela 6 - Alometria da carcaça, dos tecidos não-componentes da carcaça e dos cortes comerciais, em relação ao peso do corpo vazio (PCV), de cabritos F1 Boer $\times$ Saanen

\begin{tabular}{lcccc}
\hline & Equação: $\ln \mathrm{Y}=\ln \mathrm{a}+\mathrm{b} \ln \mathrm{X}$ & Teste $\mathrm{t}(\mathrm{Ho}: \mathrm{b}=1)$ & $\mathrm{r}^{2}$ & Prob $^{1}$ \\
\hline Carcaça (CA) & $\ln \mathrm{CA}=-0,7152+1,0368 \ln$ PCV & $=$ & 0,94 & NS \\
Não-carcaça (NC) & $\ln \mathrm{NC}=-0,7327+0,9646 \ln$ PCV & $=$ & 0,94 & NS \\
Perna (PN) & $\ln \mathrm{PN}=-2,7151+1,0999 \ln$ PCV & $=$ & 0,96 & NS \\
Lombo (LO) & $\ln \mathrm{LO}=-4,1865+1,2709 \ln$ PCV & $>$ & 0,96 & $\mathrm{P}<0,001$ \\
Costelas (CO) & $\ln \mathrm{CO}=-3,2314+1,2265 \ln$ PCV & $>$ & 0,97 & P \\
Paleta (PA) & $\ln$ PA $=-2,8717+0,9852 \ln$ PCV & $=$ & 0,95 & NS \\
Pescoço (PE) & $\ln$ PE $=-3,6929+1,0295 \ln$ PCV & $=$ & 0,93 & NS \\
\hline
\end{tabular}

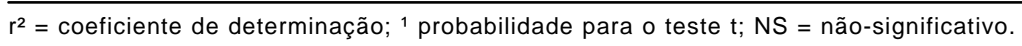

parte, a variação numérica e/ou estatística que normalmente se observa ao avaliar o crescimento dos tecidos ósseo, muscular e adiposo em relação a um componente regional (corte comercial) e em relação ao PCV. Para gordura, o coeficiente de crescimento em relação à perna foi de 1,70 e, em função do PCV, foi de 1,88, superiores aos obtidos por Teixeira et al. (1995) em cabritos da raça Serrana. Esses resultados podem ser relacionados às características produtivas da raça Boer, transmitida aos cabritos F1 utilizados nesta pesquisa, que, de acordo com Oman et al. (1999), são animais de excelente conformação para produção de carne, sendo recomendada por Malan (2000) como raça melhoradora em cruzamentos com caprinos nativos.

Mahgoub \& Lodge (1996) avaliaram o crescimento de cabritos castrados e não-castrados pesando ao abate 11,18 e $28 \mathrm{~kg}$ e verificaram que o tecido muscular da perna cresceu na mesma proporção do corpo, com coeficiente de alometria de 0,94 para machos, 0,99 para fêmeas e 1,04 para castrados, enquanto o coeficiente para gordura, na carcaça, foi de 1,72 para as fêmeas, 1,65 para os castrados e 1,25 para os nãocastrados.

Os coeficientes de crescimento para gordura subcutânea e intermuscular, em relação à perna, foram respectivamente de 1,92 e 1,47 (Tabela 7), abaixo dos 2,15 para gordura subcutânea e acima dos 1,34 para intermuscular obtido por
Yáñez (2002) com cabritos Saanen. Mtenga et al. (2002), trabalhando com animais da raça Saanen Britânica avaliados com PV variando de $3,50 \mathrm{~kg}$ até $72,50 \mathrm{~kg}$, demonstraram que a gordura de cobertura apresentou crescimento mais tardio que o da intermuscular. Estas diferenças podem ser atribuídas a aspectos como maturidade fisiológica (Butterfield, 1988), peso de abate e grupo genético (Warmington \& Kirton, 1990) e castração (Yáñez, 2002).

De acordo com Church (1993), o crescimento dos ruminantes pode ser dividido em três etapas. A primeira, correspondente do nascimento ao aleitamento ou desmame, é inicialmente caracterizada pelo funcionamento do trato gastrintestinal como monogástrico, que vai até a completa formação dos pré-estômagos, que só ocorre após o desaleitamento. A segunda etapa de crescimento consiste do período do desmame até a puberdade e a última etapa consiste no acabamento, ou terminação. Todas essas fases influenciam a taxa de crescimento corporal e a composição física e química desse crescimento e, de acordo com Yáñez et al. (2006b), altera as características organolépticas da carne.

Os cabritos de $5 \mathrm{~kg}$ apresentaram desenvolvimento ósseo avançado e a variação na proporção do tecido muscular pode ser reflexo do crescimento fetal (Warmington \& Kirton, 1990), enquanto os animais de $10 \mathrm{~kg}$ de PV apresen- 
Tabela 7 - Alometria dos componentes teciduais, músculo, osso, gordura, gordura subcutânea e gordura intermuscular da perna de cabritos F1 Boer $\times$ Saanen em relação ao peso da perna (PP) e do peso de corpo vazio (PCV)

\begin{tabular}{|c|c|c|c|c|}
\hline & Equação: $\ln Y=\ln a+b \ln X$ & Teste $t($ Ho: $b=1)$ & $\mathrm{r}^{2}$ & $\operatorname{Prob}^{1}$ \\
\hline \multicolumn{5}{|c|}{ Em relação ao peso da perna (PP) } \\
\hline Músculo (M) & $\ln \mathrm{M}=-0,7224+1,0495 \ln \mathrm{PP}$ & $=$ & 0,96 & NS \\
\hline Osso (O) & $\ln \mathrm{O}=0,5821+0,6855 \ln \mathrm{PP}$ & $<$ & 0,94 & $\mathrm{P}<0,01$ \\
\hline Gordura (G) & $\ln G=-7,6009+1,6958 \ln P P$ & $>$ & 0,90 & $\mathrm{P}<0,05$ \\
\hline Gordura subcutânea (GS) & $\ln \mathrm{GS}=-9,8265+1,9182 \ln \mathrm{PP}$ & $>$ & 0,88 & $\mathrm{P}<0,01$ \\
\hline Gordura intermuscular (GS) & $\ln \mathrm{GI}=-6,8124+1,4719 \ln \mathrm{PP}$ & $>$ & 0,87 & $\mathrm{P}<0,1$ \\
\hline \multicolumn{5}{|c|}{ Em relação ao peso de corpo vazio (PCV) } \\
\hline Músculo (M) & $\ln \mathrm{M}=-4,3982+1,1564 \ln \mathrm{PCV}$ & $=$ & 0,95 & NS \\
\hline Osso $(\mathrm{O})$ & $\ln \mathrm{O}=-1,8189+0,7551 \ln \mathrm{PCV}$ & $<$ & 0,94 & $\mathrm{P}<0,01$ \\
\hline Gordura (G) & $\ln \mathrm{G}=-13,8155+1,8756 \ln \mathrm{PCV}$ & $>$ & 0,90 & $\mathrm{P}<0,05$ \\
\hline
\end{tabular}

$\mathrm{r}^{2}=$ coeficiente de determinação; ${ }^{1}$ probabilidade para o teste $\mathrm{t} ; \mathrm{NS}=$ não significativo

taram trato gastrintestinal ainda em desenvolvimento. Em média, as idades de abate foram 14, 48, 66, 77 e 113 dias, respectivamente, para os animais com $5,10,15,20$ e $25 \mathrm{~kg}$ de PV. Portanto, os animais foram abatidos muito jovens e antes da puberdade, período em que a taxa de deposição de massa muscular supera o ritmo de acúmulo de gordura.

A interpretação do crescimento animal pela curva alométrica reduz todas as informações sobre o valor do coeficiente de crescimento alométrico "b" (Berg \& Butterfield, 1976), no entanto, de acordo com Butterfield (1988), a eficiência desse modelo depende da maturidade e da condição fisiológica dos animais, pois o princípio básico é que a parte e o todo apresentem o mesmo ritmo de crescimento no intervalo de peso estudado.

Nos resultados obtidos e na discussão desenvolvida, devem ser considerados desde os interesses econômicos dos produtores até as exigências dos consumidores. Neste contexto, o baixo teor de gordura da carne caprina e a pouca gordura de cobertura na carcaça não comprometeria os interesses dos consumidores, que parecem exigir carne magra, porém suculenta e macia. Portanto, esses resultados devem ser associados a outros descritos na literatura e obtidos em pesquisas sobre a qualidade da carne segundo os efeitos da idade e do peso de abate, da castração, da restrição alimentar, do teor e da qualidade da gordura presente na carne.

$\mathrm{Na}$ definição dos pesos de abate dos animais, considerou-se a exigência de mercado da região, ou seja, carcaça em torno de 8 a $12 \mathrm{~kg}$. Neste sentido, foi preconizado que o peso vivo máximo deveria ser de $25 \mathrm{~kg}$, o que ocorreu com menos de 120 dias de idade, antes mesmo de atingirem a maturidade fisiológica e desta forma, refletindo em bom desenvolvimento dos animais. Diante desses resultados, recomenda-se que em outros trabalhos dessa natureza sejam incluídos animais com pesos mais elevados.

\section{Conclusões}

Para obtenção de carcaça com rendimento acima de $44 \%$ e adequada proporção de músculo e gordura subcutâneaque proteja a carcaça durante o resfriamento, recomenda-se abater os animais com 20 e $25 \mathrm{~kg}$ de peso vivo, correspondente a carcaças de 8 a $11 \mathrm{~kg}$. Todavia, se o objetivo é obter carcaças mais leves, recomenda-se o abate ao final do aleitamento, com peso vivo em torno de $10 \mathrm{~kg}$. Em cabritos de 5 a $25 \mathrm{~kg}$ de PV, a paleta, o pescoço e a perna crescem na mesma proporção do corpo; as costelas e o lombo mais lentamente que o corpo; os ossos da perna mais rapidamente que a perna; os músculos igualmente; e a gordura se desenvolve mais lentamente que a perna.

\section{Literatura Citada}

AGRICULTURAL AND FOOD RESEARCH COUNCIL - AFRC. The nutrition of goat. Nutriction Abstract Revision. Aberdeen: 1998. v.67, n.11, 118p. (Report 10).

BERG, R.T.; BUTTERFIELD, R.M. New concept of cattle growth. Sydney: Sydney University Press, 1976. 240p.

BOGGS, D.L.; MERKEL, R.A.; DOUMIT, M.E. Livestock and carcasses. An integrated approach to evaluation, grading and selection. Kendall: Hunt Publishing Company, 1998. 256p.

BUENO, M.S.; CUNHA, E.A.; SANTOS, L.E. et al. Características de cordeiro Sulffolk abatidos em diferentes idades. Revista Brasileira de Zootecnia, v.26, n.6, p.1803-1810, 2000.

BUENO, M.S.; SANTOS, L.E.; CUNHA, E.A. et al. Avaliação de carcaça de cabritos abatidos com diferentes pesos vivos. Boletim da Indústria Animal, v.54, n.2, p.61-67, 1997.

BUTTERFIELD, R. New concept of sheep growth. Sydney: Sydney University Press, 1988. 167p.

CHURCH, D.C. El ruminante fisiología digestiva y nutrición. Zaragoza: Acribia, 1993. 641p.

COLOMER-ROCHER, F.C.; KIRTON, A.H.; MERCER, G.J. et al. Carcass composition of New Zealand Saanen goats slaughtered at different weights. Small Ruminat Research, v.7, p.161-173, 1992.

COLOMER-ROCHER, F.C.; MORAND-FEHR, P.; KIRTON, A.H.; Standard methods and procedures for goat carcass evaluation, jointing and tissue separation. Livestock Production Science, v.17, p.149-159, 1987. 
FURUSHO-GARCIA, I.F.; PEREZ, J.R.O.; BONAGURIO, S. et al. Estudo alométrico dos cortes de cordeiros Santa Inês puros e cruzas. Revista Brasileira de Zootecnia, v.35, n.4, p.1416-1422, 2006.

HAMMOND, J. Reprodución, crecimiento y herancia. In: Principios de la explotación animal. Zaragoza: Acribia, 1966. p.142-157.

HUXLEY, J.S. Problems of relative growth. Londres: Methuen, 1932. 276p.

MAHGOUB, O.; LODGE, G.A. Growth and body composition in meat production in Omani Batina goats. Small Ruminat Research, v.19, p.233-246, 1996

MAHGOUB, O.; LU, C.D. Growth, body and carcass tissue distribution in goats of large and small sizes. Small Ruminat Research, v.27, p.267-278, 1998.

MALAN, S.W. The improved Boer goat. Small Ruminat Research, v.36, p.165-170, 2000.

MTENGA, L.A.; OWEN, E.; MUHIKAMBELE, V.R.M. et al. [2002]. Growth and partition of fat depots in male British Saanen goats. Disponível em: <www.fao.org/wairdocs>. Acesso em: 10/9/2002.

OMAN, J.S.; WALDRON, D.F.; GRIFFIN, D.B. et al. Effect of breed-type and feeding regimen on goat carcass traits. Journal Animal Science, v.77, p.3215-3218, 1999.

OSÓRIO, J.C.; OSÓRIO, M.T.; JARDIM, P.O. et al.Métodos para avaliação da produção da carne ovina: in vivo, na carcaça $\mathrm{e}$ na carne. Pelotas: Editora Universitária, 1998. 107p.

PEREIRA FILHO, J.M.; RESENDE, K.T.; TEIXEIRA, I.A.M.A. et al. Efeito da restrição alimentar no desempenho produtivo e econômico de cabritos F1. Revista Brasileira de Zootecnia, v.34, n.1, p.188-196, 2005

PEREIRA FILHO, J.M.; TRINDADE, I.A.M.A.; RESENDE, K.T. et al. Biometria do trato gastrintestinal em cabritos $1 / 2$ sangue (Boer $x$ Saanen. In: REUNIÓN DA ASSOCIACIÓN LATINOAMÉRICANA DE PRODUCCIÓN ANIMAL, 17. 2001, Habana. Memorias... Habana: 2001. (CD-ROM).

SAINZ, R.D. Avaliação de carcaça e cortes comerciais de carne caprina e ovina. In: SIMPÓSIO INTERNACIONAL SOBRE CAPRINOS E OVINOS DE CORTE, 2000, João Pessoa. Anais... João Pessoa: 2000. v.1, p.237-250.
SCHÖNFEELDT, H.C.; NAUDÉ, R.T.; BOK, W. et al. Cooking and Juiciness-related quality characteristics of goat and sheep meat. Meat Science, v.34, p.381-394, 1993.

SOUSA, W.H.; LEITE, R.M.H.; LEITE, P.R.M. Raça Boer caprino tipo carne. João Pessoa, 1998. 31p.

STATISTICAL ANALYSIS SYSTEM - SAS. SAS/STAT user's guide: statistics. Cary: SAS Institute, 1999. 943p.

TEIXEIRA, I.A.M.A. Métodos de estimativa de composição corporal e exigências nutricionais de cabritos F1 Boer x Saanen . Jaboticabal: Universidade Estadual Paulista, 2004. 91p. Tese (Doutorado em Zootecnia) - Universidade Estadual Paulista, 2004.

TEIXEIRA, A.; AZEVEDO, J.; DELFA, R. et al. Growth and development of Serrana kids from Montesinho Natural Park. Small Ruminant Research, v.16, p.263-269, 1995.

TRINDADE, I.A.M.A.; PEREIRA FILHO, J.M.; RESENDE, K.T. et al. Composição corporal e exigências líquida de cabritos mestiços em aleitamento. In: Memorias. Reunión da Associación Latinoaméricana de Producción Animal, 17., Habana.Anais... Habana: 2001. (CD-ROM).

WARMINGTON, B.G.; KIRTON, A.H. Genetic and non-genetic influences on growth and carcass traits of goats. Small Ruminant Research, v.3, p.147-165, 1990.

YÁÑEZ, E.A. Desenvolvimento relativo dos tecidos e características da carcaça de cabritos Saanen, com diferentes pesos e níveis nutricionais. Jaboticabal: Universidade Estadual Paulista, 2002. 85p. Tese (Doutorado em Zootecnia) Universidade Estadual Paulista, 2002.

YÁÑEZ, E.A; FEREIRA, A.C.D.; MEDEIROS, A.N. et al. Methodologies for ribeye area determination in goats. Small Ruminant Research, v.66, p.197-200, 2006.

YÁÑEZ, E.A; RESENDE, K.T.; FERREIRA, A.C.D. et al. Restrição alimentar em caprinos: rendimento, cortes comerciais e composição da carcaça. Revista Brasileira de Zootecnia, v.35, n.5, p.2093-2100, 2006.

YÁÑEZ, E.A; RESENDE, K.T.; FERREIRA, A.C.D. et al. Effests of feed restriction on yield, retail cuts and tissue composition of carcass of Saanen kids. Revista Brasileira de Zootecnia, v.36, n.3, p.666-673, 2007 . 